University of Nebraska - Lincoln

DigitalCommons@University of Nebraska - Lincoln

Faculty Publications from the Harold W. Manter Laboratory of Parasitology

$2-2009$

\title{
Eimeria spp. in Brazilian Water Buffalo
}

Antonio Carlos F. de Noronha, Jr. FEIS/UNESP

Wilma A. Starke-Buzetti

FEIS/UNESP, starke@bio.feis.unesp.br

Donald W. Duszynski

University of New Mexico, eimeria@unm.edu

Follow this and additional works at: https://digitalcommons.unl.edu/parasitologyfacpubs

Part of the Parasitology Commons

Noronha, Jr., Antonio Carlos F. de; Starke-Buzetti, Wilma A.; and Duszynski, Donald W., "Eimeria spp. in Brazilian Water Buffalo" (2009). Faculty Publications from the Harold W. Manter Laboratory of Parasitology. 132.

https://digitalcommons.unl.edu/parasitologyfacpubs/132

This Article is brought to you for free and open access by the Parasitology, Harold W. Manter Laboratory of at DigitalCommons@University of Nebraska - Lincoln. It has been accepted for inclusion in Faculty Publications from the Harold W. Manter Laboratory of Parasitology by an authorized administrator of DigitalCommons@University of Nebraska - Lincoln. 


\title{
Eimeria Spp. in Brazilian Water Buffalo
}

\author{
Antonio Carlos F. de Noronha, Jr., Wilma A. Starke-Buzetti†, and Donald W. Duszynski, Department of Biologia e Zootecnia, FEIS/ \\ UNESP, Av. Brasil, 52, Ilha Solteira, SP 15385-000, Brazil; *Department of Biology, MSC03 2020, 1 University of New Mexico, Albuquerque, \\ New Mexico 87131-1091; †To whom correspondence should be addressed. e-mail: starke@bio.feis.unesp.br
}

ABSTRACT: Eimeria species are frequently found in water buffalo ( $\mathrm{Bu}$ balus bubalis) in Brazil. Here, we report those Eimeria spp. that infect buffalos during their first year of life. Fresh fecal samples were examined from 2 groups ( 1 group/yr for 2 yr, 2000-2002), each with 18 water buffalo calves (both sexes), from birth through 12 mo of age, in Selvíria, MS, Brazil. Five oocyst morphotypes were observed, i.e., Eimeria ellipsoidalis and Eimeria zuernii, both previously described from water buffalo, and 3 other morphotypes consistent with descriptions of known Eimeria spp. from Artiodactyla hosts, but originally described from other genera than those in which we found them (referred to here as Eimeria species 1-3). Our results showed that buffalo calves started shedding oocysts in their feces between 6-29 days of age, with the highest concentration ranging from 188-292 oocysts/g of feces. The 3 unnamed oocyst morphotypes in the calf feces resembled E. auburnensis (Eimeria sp. 3), E. cylindrica (Eimeria sp. 1), and E. subspherica (Eimeria sp. 2). The most prevalent species were Eimeria sp. 1 and $E$. ellipsoidalis, which dominated in the youngest animals (6 to 133 days old). Eimeria zuernii oocysts, in contrast, were found only in low numbers in the feces of older calves (208 to 283 days old). Calves were infected more frequently during the rainy season (September to January) in both years, but cows were negative for Eimeria spp., whenever feces were collected (spring, winter, autumn, or summer seasons).

Eimeria Schneider, 1875 (Apicomplexa: Eimeriidae) is a large genus of obligate intracellular parasites of the intestinal epithelium (and other sites) of most vertebrates worldwide. Eimeria spp. infect their hosts when water or food contaminated with sporulated oocysts are ingested (Roberts and Janovy, 2005). Eimeriosis in ruminants can cause high mortality and morbidity, especially in calves (Griffiths, 1974; Sanyal and Ruprah, 1984). The susceptibility of hosts to eimerian parasites depends on their age, genetic predisposition, innate or adaptive immunity, stress level, handling, location of the parasite in the intestinal epithelium, and number and location of endogenous stages, as well as climatic and other factors (Hayat et al., 1994).

In Brazil, there are many reports of bovine coccidiosis, but few have documented coccidia in water buffalo (Bubalus bubalis). Silva (1969), Costa et al. (1980), Starke et al. (1983), and Láu (1990) reported that eimeriid parasites are the most prevalent and important agents of diseases that affect the growth and development of the water buffalo. Rebouças et al. (1994), also in Brazil, noted that 36\% of buffalo calves between 15 days and 12 mo of age were infected with several Eimeria spp., and Barbosa et al. (1992) found that all of the 24 calves they examined were infected with these parasites during the first $30 \mathrm{wk}$ of life. The hot and humid Brazilian climate is advantageous to both the expansion of water buffalo herds and the high prevalence of parasites in these animals, particularly younger ones. In experimental infections of buffalo calves with Eimeria zurnii, Sanyal and Ruprah (1984) reported diarrhea, anorexia, weakness, and death 25 days after infection.

A herd of about 40 water buffalo (Bubalus bubalis) was kept for 12 mo on a 12-ha pasture of Brachiaria decumbens grass, with a pond as their water source, located in Selvíria, MS, Brazil, South America $\left(51^{\circ} 24^{\prime} 55.80^{\prime \prime} \mathrm{W}, 20^{\circ} 22^{\prime} 5.19^{\prime \prime} \mathrm{S}\right)$. The cows were not milked and the calves were kept together in this area with their mothers. From this herd, 18 water buffalo calves, both males and females, were monitored from their birth through $1 \mathrm{yr}$ of age to determine their natural infections with Eimeria spp. (2000-2001); this procedure was then repeated for a second group of 18 calves during the second year of our study (20012002).

A fecal sample from calves was collected weekly from birth to 6 mo of age and then monthly from the same animals until each was 12 mo old. Feces were taken directly from the rectum of each calf and examined in the laboratory using McMaster chambers (Whitlock, 1948) and expressed as oocysts per gram of feces (OPG). To identify Eimeria spp. in adults $(n=40)$, fecal samples were collected once during the months of January, April, July, and October to represent all the climatic seasons of the year (summer, autumn, winter, and spring).

After quantifying the Eimeria oocysts in the feces of each animal, the numbers of OPG were graded from + to +++ as follows: $+=$ $<2,500$ OPG (weak infection); $++=2,550$ to 5,000 OPG (moderate infection); and $+++=>5,050$ OPG (heavy infection). Fecal samples with $>2,550$ OPG were placed in Petri dishes containing 2\% (w/v) aqueous potassium dichromate $\left(\mathrm{K}_{2} \mathrm{Cr}_{2} \mathrm{O}_{7}\right)$ solution, mixed thoroughly, and kept 6-10 days at room temperature to allow sporulation. Feces containing sporulated oocysts were placed into glass bottles with $\sim 100$ $\mathrm{ml}$ of $\mathrm{K}_{2} \mathrm{Cr}_{2} \mathrm{O}_{7}$ solution and kept at $4 \mathrm{C}$ until they could be processed and identified (as per Duszynski and Wilber, 1997; Duszynski et al., 1999). Fecal samples from animals of the same age groups were pooled into separate bottles. Sporulated oocysts were concentrated using a centrifuge-flotation technique with a concentrated sucrose solution (Sheather, 1923) and then were counted in triplicate using a light microscope $(\times 400)$, taking 3 samples of $3 \mathrm{ml}$ from each bottle. Oocysts were identified following the guidelines of Duszynski and Wilber (1997). Standardized abbreviations for oocyst/sporocyst structures are those used by Wilber et al. (1998), except that we used SZ instead of SP for sporozoite. Oocyst characters included length (L), width (W), their range and ratio $(\mathrm{L} / \mathrm{W})$, micropyle $(\mathrm{M})$, micropyle cap $(\mathrm{MC})$, residuum $(\mathrm{OR})$, and polar granule (PG); sporocyst characters were length (L), width (W), their range and ratio (L/W), Stieda body (SB), substiedabody (SSB), parastieda body (PSB), residuum (SR), sporozoites (SZ), refractile bodies $(\mathrm{RB})$, and nucleus $(\mathrm{N})$ in SZ. Oocysts $(\mathrm{n}=20)$ were measured and photographed using bright field microscopy, and all measurements are in micrometers $(\mu \mathrm{m})$ with means followed by the ranges in parentheses.

Since the Eimeria spp. we saw, or those that they resemble, have been found in a variety of bovid host genera (Bovidae: Bovini), we have used the following abbreviations when the generic names are abbreviated: Bo (Bos) and Bu (Bubalus).

The following species were identified in buffalo calves: E. ellipsoidalis, E. species 1 (=E. cylindrica-like), E. species 2 (=E. subsphericalike), E. species 3 (E. auburnensis-like), and E. zuernii.

Eimeria ellipsoidalis (Fig. 1A) was originally described from Bo. taurus and later from several other genera and species of bovids, including water buffalos. Rebouças et al. (1990) reported it in 5\% of 24 buffalo calves, ranging from 15 days to 12 -mo-old, in Vale do Ribeira, SP, and Láu (1982) reported it and 3 other Eimeria species in Bu. bubalis in the state of Pará. Here, we found E. ellipsoidalis in $7 / 36(19 \%)$ buffalo calves 14- to 111-days-old (Table I), particularly during the months of March-April (autumn, the beginning of the dry season). The oocysts measured varied slightly in shape from ellipsoidal to slightly ovoidal, each with a thin wall that appeared to be 2-layered. Both $\mathrm{M}$ and $\mathrm{MC}$ were absent, and oocysts were $21 \times 15(18-26 \times 13-18)$ with a L/W of 1.3. Both OR and PG were absent. Sporocysts were elongateellipsoidal, slightly pointed at 1 end, and measured $12 \times 5(11-16 \times$ 5-6) with a L/W of 2.4. Both SR and SB were present, but SSB and PSB were absent. Each SZ had 2 RBs. Concordantly, Levine and Ivens (1970, 1986) made it clear that the oocysts described as E. ellipsoidalis by different authors vary considerably in size from $12-32 \times 10-29$, but with sporocysts that are less variable, i.e., 11-17 $\times 5-7$. This species is considered common in water buffalo and other bovids (Soulsby, 1968).

Oocysts and sporocysts of Eimeria species 1 (Fig. 1B) have the following features. Oocyst shape $=$ elongate-ellipsoidal with thin, smooth wall composed of 2 layers; M, 3 wide, appears to be present; MC: absent; L $\times \mathrm{W}: 20 \times 15(16-30 \times 12-17) ; \mathrm{L} / \mathrm{W}: 1.4 ; \mathrm{OR}, \mathrm{PG}$ : both absent. Sporocyst shape $=$ elongate-ellipsoidal, slightly pointed at 1 end; L $\times$ W: $10 \times 5(9-13 \times 4-6)$; L/W: 2.0; SR: present; SB: present; SSB, PSB: both absent. These descriptive parameters resemble those of E. cylindrica Wilson, 1931, to some degree. In the original description of E. cylindrica, the micropyle (M) was said to be "unapparent" and in later descriptions to be absent (Levine and Ivens, 1986), and none 


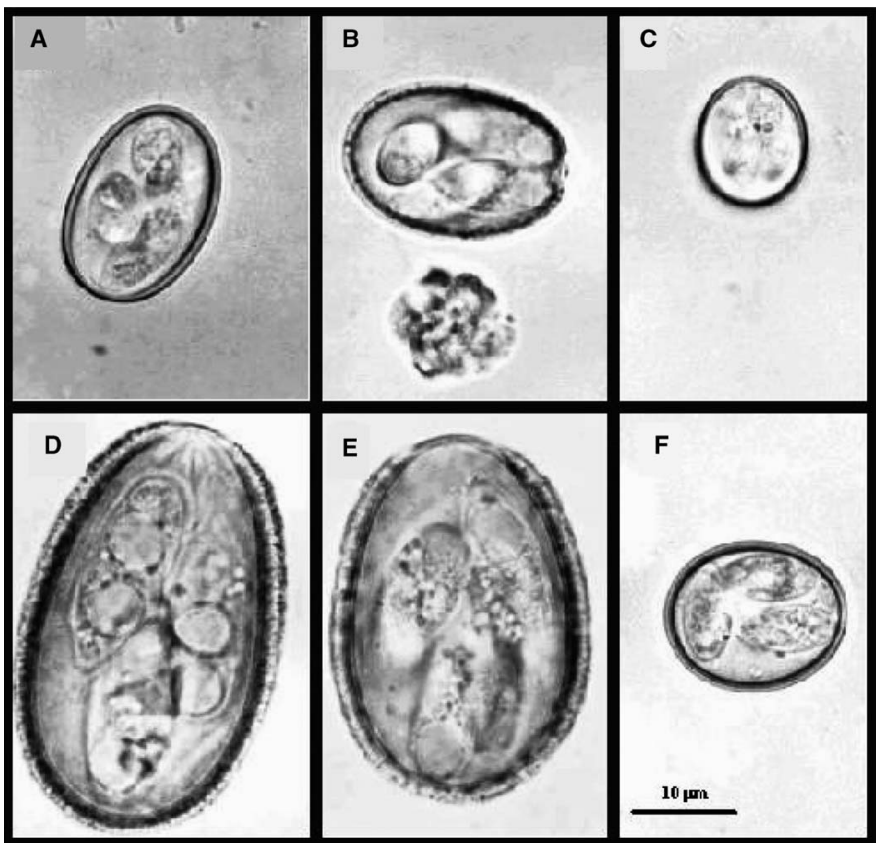

FIGURE 1. Photomicrographs of sporulated oocysts identified in the feces of buffalo calves born in Selviria, MS, Brazil. (A) Eimeria ellipsoidalis; (B) E. sp. 1 (E. cylindrica-like); (C) E. sp. 2 (E. subsphericalike); (D, E) E. sp. 3 (E. auburnensis-like); and (F) E. zuernii. Bar = $10 \mu \mathrm{m}$. of the published line drawings of this species shows an M (e.g., Christensen, 1941; Joyner et al., 1966; Levine and Ivens, 1967; Sayin, 1969). The species we observed clearly has an M. Another qualitative difference is that oocysts of E. cylindrica are reported to have a PG of many small fragments, which we did not see. Oocysts of E. cylindrica were first described from Bo. taurus and later reported from Bo. indicus and $B u$. babalis. Levine and Ivens (1970) speculated that the form reported from water buffalo in India may be a separate species from $E$. cylindrica in Bo. taurus in the U.S.A. Prior to the present study, Rebouças et al. (1990) reported E. cylindrica in $4 \%$ of 24 buffalo calves, ranging from 15 days to 12-mo-old, in Vale do Ribeira, SP. Rather than assume the form we saw in $B u$. bubalis actually is the one that infects Bo. taurus, or assume that it is not and call it a new species, we think it best at this time to document its presence in the water buffalo in Brazil and wait until molecular evidence is available to clarify the situation. In the animals we observed, this was the most abundant species in buffalo calves between 6 and 133 days old, being found in 8/36 (22\%) calves, particularly during the first 2 mo of age (Table I).

Eimeria species 2 somewhat resembled E. subspherica Christensen, 1941 (Fig. 1C). Oocyst shape $=$ subspherical; thin, smooth wall with 2 layers; M, MC: both absent; $\mathrm{L} \times \mathrm{W}: 15.5 \times 12.7(11-19 \times 10-16)$; L/W: $1.2(1.0-1.5)$; OR, PG: both absent. Sporocyst shape $=$ ovoidal to ellipsoidal, pointed at 1 end; $\mathrm{L} \times \mathrm{W}: 6.6 \times 2.9(5-12.5 \times 2.5-4)$; L/W: 2.3 (1.3-3.0); SR: absent; SB: present; SSB, PSB: both absent; 2 $\mathrm{RB}$ in SZ. These oocysts differed from the original description in being slightly larger in both range and mean dimensions $(11-19 \times 10-16$ [15.5 $\times 12.7]$ vs. $9-14 \times 8-13[12 \times 11])$, while their sporocysts are similar in size. Eimeria subspherica is generally considered to be nonpathogenic under field conditions (Levine and Ivens, 1970). Our E. subpherica-like oocysts were present in only $2 / 36(7.5 \%)$ younger buffalo calves (first 2 mo of age) in small numbers (Table I).

The oocysts and sporocysts of Eimeria species 3 (Figs. 1D, E) have the following features. Oocyst shape $=$ elongate-ovoidal; wall with 2 layers, 2.8 (2.5-4.0) thick; outer brown, with rough appearance; M: present, 4.8 (4-6) wide; MC: absent; L $\times$ W: $35 \times 22(32-46 \times 19-$ 28); L/W: 1.59 (1.3-1.6); OR, PG: both absent. Sporocyst shape $=$ elongate-ellipsoidal, pointed at 1 end; $\mathrm{L} \times \mathrm{W}: 12.5 \times 5.0(9-16 \times 4-$ 6); L/W 2.5 (2-4); SR: present, often as an irregular mass of globules

TABLE I. Mean numbers of oocysts of 5 Eimeria spp. identified in water buffalo (Bubalus bubalis) calves of different ages from birth through 12 mo of age, in Selvíria, MS, Brazil during 2 consecutive years $(2000,2001)$, combined.

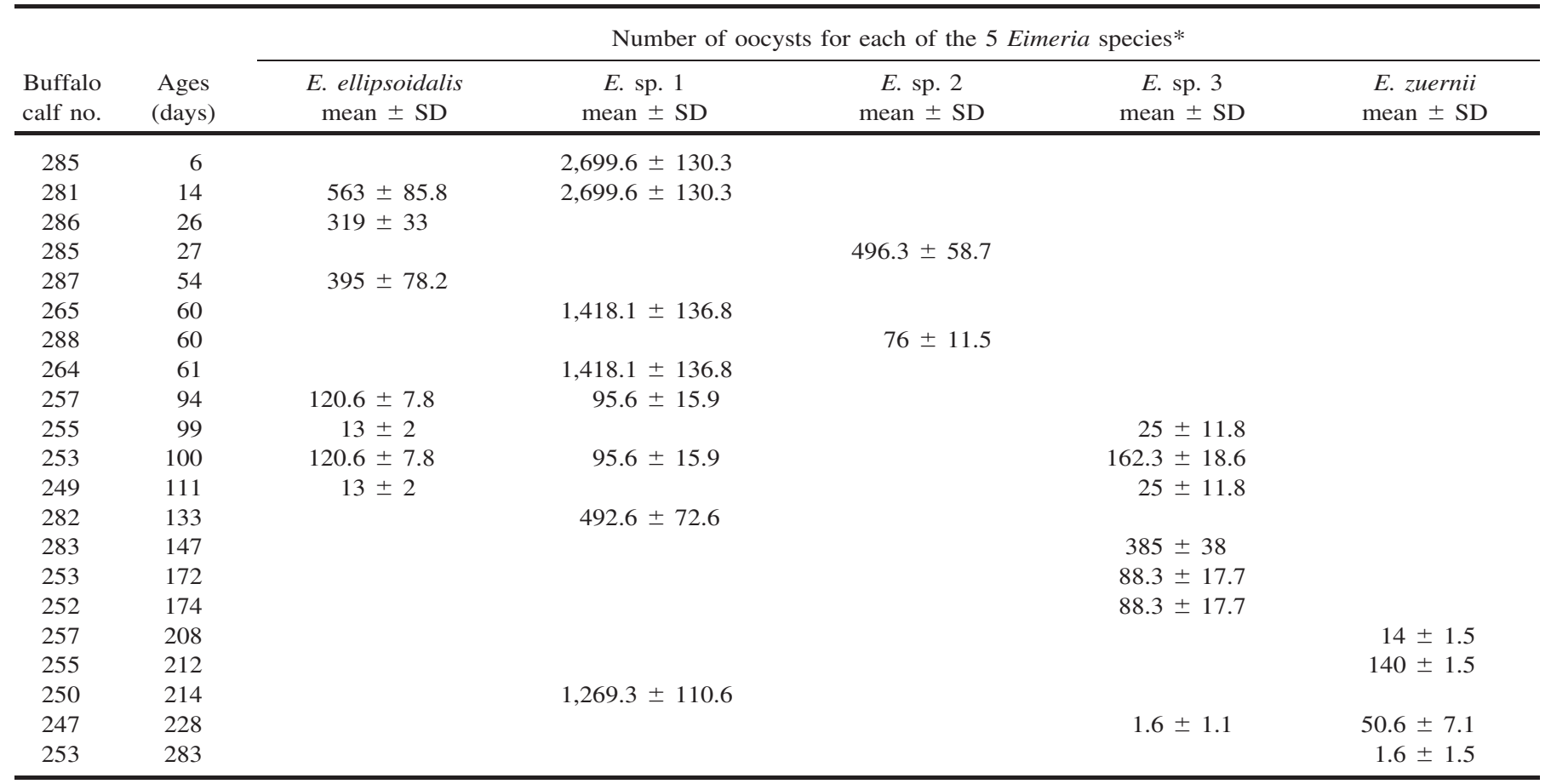

* Oocysts $/ 3 \mathrm{ml}$ of fecal material $\pm \mathrm{SD}$ (standard deviation) 


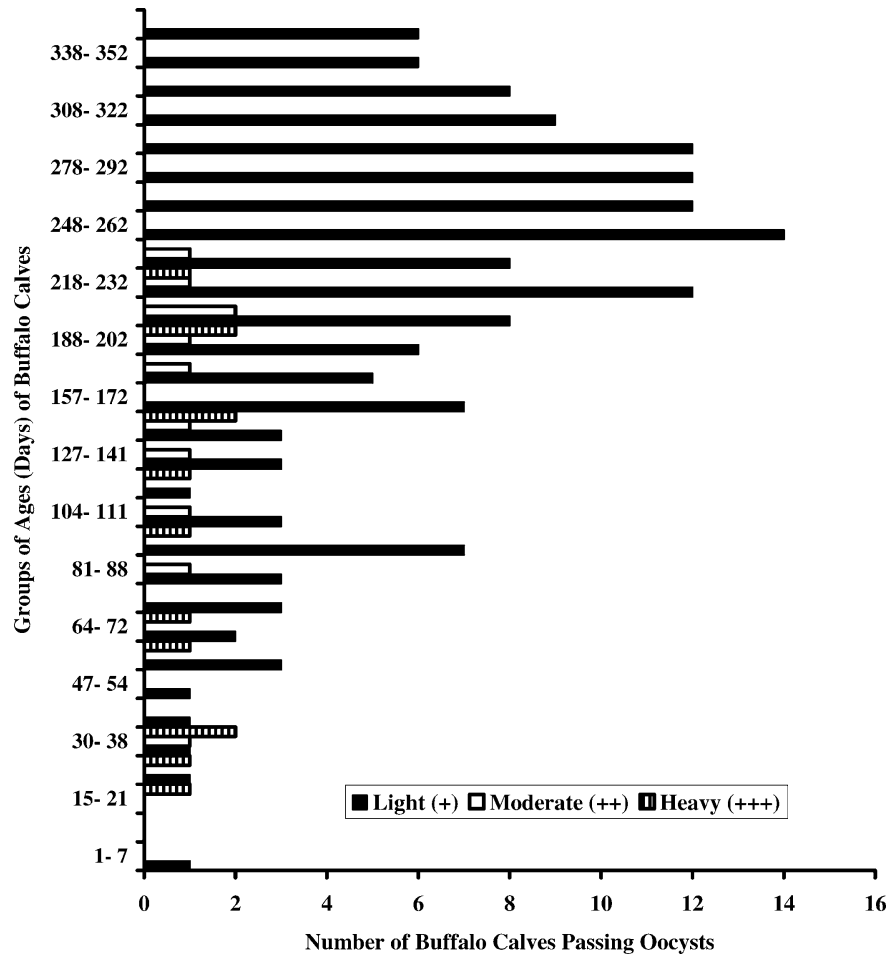

FiguRE 2. Mean numbers of buffalo calves, positive for eimerian oocysts in their feces during the $2 \mathrm{yr}$ of examination $(2000,2001)$ according to their ages and grade of infection; light $(+)$, moderate $(++)$, and heavy $(+++)$, obtained in Selvíria, MS, Brazil.

along one margin of sporocyst; SB: present as a darkened structure at pointed end; SSB, PSB: both absent; SZ each with 2 round RB. These structural features resemble those of E. auburnensis Christensen and Porter, 1939, except that our sporocysts were smaller, in both range and mean, than those in previous descriptions $(9-16 \times 4-6[12.5 \times 5.0]$ vs. $16-23 \times 7-11$ [ 18 or $19 \times 8$ or 9]). Another potential difference is that our oocysts had a thick, sculptured wall (Figs. 1D, E). Levine and Ivens (1970) said the oocyst wall is "smooth, rarely rough or heavily mammillated"; however, the original drawing by Christensen and Porter (1939) showed a heavily mammillated outer wall even though they reported finding both smooth, heavily mammillated, and intermediate forms resulting from their infection experiments. Another difference is that we did not see a PG, whereas the original description says a PG is present as 1 large, or many small, scattered fragments. Finally, SZ reported from other hosts described only $1 \mathrm{RB}$, whereas our SZ clearly have 2 round RB each (Figs. 1D, E). Eimeria auburnensis has been reported to infect cattle (Bo. taurus) and water buffalo (Bu. bubalis), as well as the zebu (Bo. indicus), but no cross-transmission work has been done to substantiate this assertion. It is possible that this species is actually E. auburnensis and is capable of infecting multiple host genera that are closely related. Because of structural differences noted here, we believe it best at this time to only document its presence in Bu. bubalis and wait until molecular data can provide evidence that this is either 1 , or multiple, species. This species is known to produce a moderate degree of pathogenicity, including slight diarrhea and apathy, in young calves (Bo. taurus). In our study, E. sp. 3 was found in 7/36 (19\%) older animals, 99- to 122-days-old, but only in small numbers (Table I).

Eimeria zuernii (Fig. 1F) was originally described from Bo. taurus and was later reported from Bo. indicus (zebu) and Bu. bubalis (water buffalo). Sayin (1969) infected 3-wk-old Bo. taurus calves with oocysts from water buffalo. Levine and Ivens $(1970,1986)$ pointed out that the oocysts described as E. zuernii by various authors differ considerably in size from $12-29 \times 10-21$, with means that vary from $17-20 \times 14$ 17. The sporocysts of E. zuernii are less variable in size, i.e., 7-13 $\times$ 4-7. The oocysts we saw and measured (Fig. 1F) were sub-spheroidal,

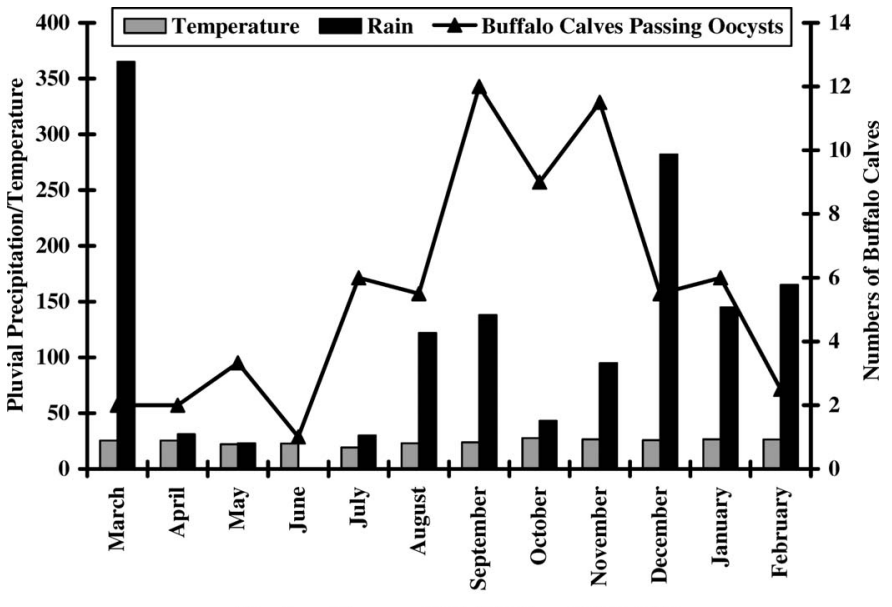

Months of the year 2000 (M-D) and 2001 (J-F)

FIGURE 3. Mean numbers of buffalo calves, positive for eimerian oocysts and pluvial precipitation $(\mathrm{mm})$ and temperature $(\mathrm{C})$ of each month (March-December 2000 and January-February 2001), obtained in Selvíria, MS, Brazil.

with a wall $\sim 1$ thick composed of 2 layers, outermost being smooth. Both an M and MC are absent. Our oocysts were $20 \times 15(15-29 \times$ 12-20) with L/W: 1.35 . OR was absent, but 1 or more PGs were present. Sporocysts were elongate-ovoidal, $9 \times 5(7-10 \times 4-7)$ and L/W, 1.8 . A tiny SB is present, but SSB and PSBs are both absent. Each sporocyst had an SR present as tiny globules or granules. This is at least the third time E. zuernii has been found in Brazil (Láu, 1982; Rebouças et al., 1990). In this study of natural infections, it was found in $4 / 36(11 \%)$ older buffalo calves, 208-283 days of age (Table I), and only in the months of October-November (summer season).

Prevalence of eimerian species was analyzed in 2 groups of buffalo calves just after their birth and then following until they reached $1 \mathrm{yr}$ of age in 2000 and 2001 (Fig. 2). Of 18 calves examined in 20002001, only 1-3 (6-17\%) calves between 22- and 156-days-old had Eimeria spp. oocysts in their feces, with a light $(+)$ intensity of infection in the most of them. When the calves were 157- to 367-days-old, 5-14 $(28-78 \%)$ shed oocysts, but still in small numbers. In 2000, only $1(6 \%)$ and $2(17 \%)$ calves had intensities of ++ or +++ ; respectively, and they were between 55- and 232-days-old. During 2001, we saw a pattern of infection similar to that in 2000 , with only a slightly higher prevalence, and with more infected animals and more intense infections, ranging from moderate $(++)$ to heavy $(+++)$ between $15-247$ days of age. In addition, in 2001,2 calves $(11 \%)$ had oocysts in their feces earlier, at 7-days-old. The largest number of calves was infected from 157-337 days (5-12 in 2000, 7-16 in 2001). However, because the pattern of infection was similar, the data for the $2 \mathrm{yr}$ were combined (Fig. 2). Barbosa et al. (1992), in São Paulo, found 58\% of buffalo calves infected with Eimeria spp. during the first 21 days after birth and $100 \%$ during the first $30 \mathrm{wk}$. These authors did not identify which Eimeria spp. infected the buffalo they examined, but they suggested that calves could be infected soon after birth, possibly during suckling, by ingesting oocysts adhering to the udder of the cows.

In our herds, most buffalo calves are born in February and March, with a few born as late as April; here, each calf was examined for $1 \mathrm{yr}$ after its birth. The distributions of infected calves/mo are given for 2000-2001 and 2001-2002 (Figs. 3, 4, respectively). For calves born in 2000, 2 peaks of infected calves occurred between September and November (rainy season) when the calves were $\sim 5$ - to 10-mo-old. However, most calves examined had only light infections $(<2,500 \mathrm{OPG})$. During 2001, the pattern of infection was similar, but a higher number of calves were infected from September to January. From June to October 2001, there was unusually low rainfall $(<50 \mathrm{~mm})$, and grass on the pasture was very dry. For that reason, the herd was kept in a smaller area, where the buffalo received supplementary food. This resulted in a higher concentration of animals $/ \mathrm{m}^{2}$ and may have contributed to more environmental contamination with oocysts, thus increasing both their availability and the exposure of animals to infection. On the other hand, 


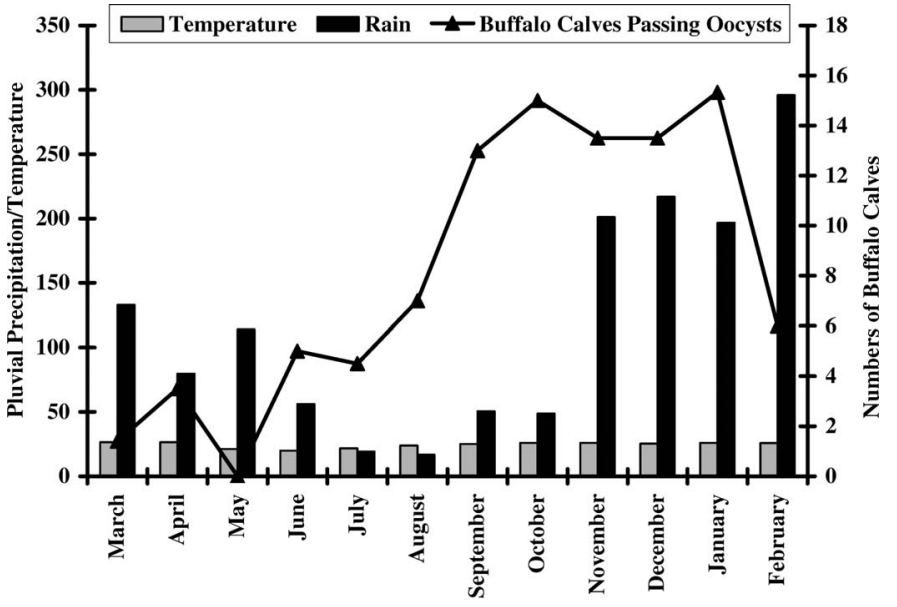

Months of the year 2001 (M-D) and 2002 (J-F)

FiguRE 4. Mean numbers of buffalo calves, positive for eimerian oocysts and pluvial precipitation $(\mathrm{mm})$ and temperature $(\mathrm{C})$ of each month (March-December 2001 and January-February 2002), obtained in Selvíria, MS, Brazil.

more rain fell from November to February $(>200 \mathrm{~mm}$ ), and not only did the numbers of infected animals increase, but infection maintained a high plateau until January, before decreasing dramatically (Fig. 4).

According to Hayat et al. (1994), the susceptibility of animals to coccidiosis depends on genetic predisposition, innate or adaptive immunity, stress level, and handling, as well as on climatic and other factors. High temperatures (mean $=25-27 \mathrm{C}$ ) and high levels of humidity (110-350 mm pluvial precipitation) occurred in Selviria, MS, during the rainy season (summer) and during the time of our study (Figs. 3, 4). These environmental conditions may have contributed optimal conditions for oocyst sporulation and, thus, for buffalo infection

In conclusion, buffalo calves from Selvíria, MS, Brazil were found infected with 5 forms of Eimeria. Age appears to have some influence on the intensity of the infection, and older calves were more resistant to infection than younger ones. Eimeria ellipsoidalis and E. sp. 2 were more prevalent in younger calves (6- to 133-days-old), while E. zuernii occurred only in low intensity in older calves (208- to 283-days-old). Infected calves did not show any clinical symptoms of coccidiosis. In both 2000 and 2001, higher numbers of animals were found infected during the rainy season (September to January). There was a decrease in the number of infected animals during the month with the lowest pluvial precipitation, suggesting that in the region studied, environmental conditions (particularly rain) can affect oocyst sporulation and pasture contamination. Adult animals did not discharge oocysts in their feces during either year.

The authors express thanks to FAPESP (Fundação de Apoio à Pesquisa do Estado de São Paulo), which funded this research.

\section{LITERATURE CITED}

Barbosa, M. A., A. C. Blasi, M. R. Oliveira, and F. M. A. Correa. 1992. Natural parasitism of buffaloes in Botucatu, SP, Brazil. III. Dynamics of gastrointestinal parasitism in cows and their calves. Memórias do Instituto Oswaldo Cruz, Rio de Janeiro 87: 37-41.

Christensen, J. F. 1941. The oocysts from domestic cattle in Alabama (U.S.A.) with descriptions of two new species. Journal of Parasitology 27: 203-220.

- AND D. A. Porter. 1939. A new species of coccidium from cattle, with observations on its life history. Proceedings of the Helminthological Society of Washington 6: 45-48.

Costa, A. J., L. J. Pacola, I. G. Arantes, J. Dohara, and C. L. Justo. 1980. Gastrointestinal helminths and their development in Indian buffaloes (Bubalus bubalis L.) born in Sertãozinho, São Paulo, Brazil. Boletin Industria Animal, Nova Odessa, SP, Brazil. 37: 195205.

Duszynski, D. W., S. J. Upton, And L. Couch. 1999. The coccidia of the world: http://biology.unm.edu/biology/coccidia/home.html.

— AND P. G. WILBER. 1997. A guideline for the preparation of species descriptions in the Eimeriidae. Journal of Parasitology 83: 333-336.

GRIFFITHS, R. B. 1974. Parasites and parasitic diseases. In The husbandry and health of the domestic buffalo, W. R. Cockrill (ed.). United Nations Food \& Agriculture Organization, Rome, Italy, p. $260-262$.

Hayat, C. S., A. Ruknudin, B. Hayat, and M. Akhtar. 1994. Prevalence of coccidiosis in cattle and buffaloes with emphasis on age, breed, sex, season and management. Pakistan Veterinary Journal 14: $214-217$.

Joyner, L. P., C. C. Norton, S. F. M. Davies, and C. V. Watkins. 1966. The species of coccidia occurring in cattle and sheep in the south-west of England. Parasitology 56: 531-541.

LÁu, H. D. 1982. Eimerídeos parasitos de búfalos no Estado do Pará. Boletim de Pesquisa Embrapa-CPATU 42: 1-11.

- 1990. Common buffalo diseases in Amazonian Brazil. Buffalo Bulletin 9: 75-77.

Levine, N. D., AND V. Ivens. 1967. The sporulated oocysts of Eimeria illinoisensis n. sp. and of the other species of Eimeria of the ox. Journal of Protozoology 14: 351-360.

, AND 1 1970. The coccidian parasites (Protozoa, Sporozoa) of ruminants. Illinois Biological Monographs, 279 p.

—, AND — 1986. The coccidian parasites (Protozoa, Apicomplexa) of Artiodactyla. Illinois Biological Monographs, $265 \mathrm{p}$.

Rebouças, M. M., T. U. FujiI, V. Amaral, S. M. Santos, E. Spósito FILHA, L. A. BARCI, AND T. FuJII. 1990. Coccidia in buffaloes $(B u-$ balus bubalis L.) of the Vale do Ribeira region, São Paulo State, Brazil. Arquivos Instituto Biológico, São Paulo 57: 1-3.

, L. M., P. S. Grasso, E. Spósito Filha, V. Do Amaral, S. M. SANTOS, AND P. M. SILVA. 1994. Prevalência e distribuição de protozoários do gênero Eimeria (Apicomplexa: Eimeriidae) em bovinos nos municípios de Altinópolis, Taquaritinga, São Carlos e Guairá. Revista Brasileira de Parasitologia Veterinária 3: 125-130.

RoBERTS, L. S., AND J. JANOVY, JR. 2005. Foundations of parasitology, 7th ed. McGraw-Hill Companies, Inc., Boston, Massachusetts, $702 \mathrm{p}$.

SANYAL, P. K., AND N. S. RupRaH. 1984. Endogenous stages and pathology in Eimeria zurnii coccidiosis in buffalo calves. Sri Lanka Veterinary Journal 32: 22-25.

SAYIN, F. 1969. The sporulated oocysts of Eimeria ankarensis n. sp. and of other species of Eimeria from buffalo cow to calves. Ankara Üniversitesi Veterinary Fakültesi dergisi 15: 282-300.

SHEATHER, A. L. 1923. The detection of intestinal protozoa and mange parasites by a flotation technique. Journal of Comparative Pathology 36: $266-275$.

SiLVA, R. G. 1969. Preliminary studies of the epidemiology of nematode parasites in buffalo (Bubalus bubalis L.) in the State of Pará. Pesquisa Agropecuária Brasileira 4: 155-160.

SoulsBy, E. J. L. 1968. Helminths, arthropods and protozoa of domesticated animals, 6th ed. Bailliere, Tindall and Cassell, Ltd., London, U.K., 824 p.

Starke, W. A., R. Z. Machado, M. R. Honer, and M. C. Zocoller. 1983. Natural course of gastrointestinal helminthic infections in buffaloes in Andradina County (SP), Brazil. Arquivos Brasileiros de Medicina Veterinária e Zootecnia 35: 651-664.

Wilber, P. G., D. W. Duszynski, S. J. Upton, R. S. Seville, and J. O. CoRLISS. 1998. A revision of the taxonomy and nomenclature of the Eimeria spp. (Apicomplexa: Eimeriidae) from rodents in the Tribe Marmotini (Sciuridae). Systematic Parasitology 39: 113-135.

WhitLock, H. V. 1948. Some modifications of the McMaster helminth eggs; counting technique and apparatus. Journal of Helminthology 29: $177-180$. 